\title{
Treasury Forecasts of Company Tax Revenue: Back of the Envelope or Back to the Drawing Board?
}

\author{
Sinclair Davidson ${ }^{1}$
}

The last decade has seen Treasury make large forecast errors when forecasting company tax receipts. This paper demonstrates the source of those errors: Treasury does not model the actual company tax base but rather estimates growth rates for aggregate measures and then makes ad hoc adjustments to Gross Operating Surplus to estimate taxable income. The consequence of this forecasting strategy is that Treasury does not have a detailed understanding of the company income tax.

\section{Introduction}

In May 2012 Treasury announced that it would be undertaking a formal review of its forecasting performance (Uren 2012). In particular there was concern that Treasury had been 'overestimating company tax revenue' (Uren and Creighton 2012). Company tax revenue has fallen short of Treasury forecasts in the years since the global financial crisis (GFC). Prior to the GFC, Treasury tended to underestimate company tax-revenue receipts. These forecast errors can have a substantial impact on the budget bottom line as Australia has a high ratio of company tax revenue to GDP by OECD standards (Clark, Pridmore and Stoney 2007).

Some level of error is unavoidable; the important question is why these errors occur and whether they are systematic. I present the argument below that the forecast errors occur because Treasury does not actually model the Australian company tax base. Rather, it bases forecasts on private Gross Operating Surplus (GOS) and then makes several ad hoc adjustments to approximate the company tax base. In retrospect, this method is highly inaccurate. It is an open question, however, whether structural modelling of the company tax base would provide better forecasts of company tax receipts.

\footnotetext{
1 RMIT University and Institute of Public Affairs, sinclair.davidson@rmit.edu.au I would to thank Jonathan Boymal, William Coleman, Ashton de Silva and Paul Lindwall for valuable comments on an earlier version of this paper.
} 
In the next section I set out how Treasury describes its methodology. Section three shows the extent of forecast errors. Section four discusses whether Treasury models the company tax base or not. I then discuss why these results matter and section six concludes.

\section{How Treasury describes what it does}

The Treasury forecasting method is described in an appendix to the 'Budget Papers Statement Five: Revenue'. The latest Budget Papers (2012/13: 5-42) state:

Most of the large and complex heads of revenue, such as personal and company income taxes are forecast by mapping appropriate economic parameter growth rates to the various income, expense and deduction items on the relevant tax returns. An estimate of total tax payable is then calculated by applying the statutory rates to the estimated income base.

Treasury identifies three potential sources of forecast error. First, its initial growth forecasts may be incorrect. That statement covers a multitude of possible biases. Second, translating economic forecasts into taxation-receipts forecasts can give rise to errors. This relates to the actual method Treasury employs to approximate the company tax base given its growth forecasts. If the method closely approximates the tax base, these errors should be small. Finally, Treasury argues that unexpected events and unexpected policy changes give rise to forecast errors. This, of course, must always be true and this source of forecast error is unavoidable. Over and above these three sources of forecast error, timing issues may also play a role in forecast errors - but over a budget cycle timing errors are less likely to be of concern as they would likely 'wash out' over the forward-estimates period.

\section{Company income tax receipt forecasts}

Table 1 shows estimates, forecasts and actual company income-tax receipts for each year from 2001/02 to 2012/13. The Budget Papers do include additional information ('Projections') but I have not captured that data. In each year, the forecast receipts for that year (shown in bold in the table), the trailing estimate for the previous year, the forecast for the next year, and the actual receipts (underlined) are captured. The rows contain data reported in each year, while the columns show the estimate, forecast or actual receipts for each year.

For example, looking at the row '2012/13 Budget Papers', the Budget Papers forecast 2012/13 company income-tax receipts to be $\$ 73480$ million while the 
actual receipts for 2010/11 were \$56 262 million. The row '2010/11 Budget Papers' indicates that the Budget Papers had forecast company income-tax receipts to be $\$ 66520$ million in that year. The row marked 'Forecast Error' represents the difference between the actual receipt and the forecast receipt. It is possible to estimate the forecast revision by comparing the forecast for each year with the forecast of the previous year. For example in 2011/12, the Budget Papers showed a one-year-out forecast of \$78 140 million for 2012/13, while in 2012/13 the forecast was $\$ 73480$ million. The difference is shown in the row labelled 'One-year Revisions'.

The forecast errors can be divided into pre-2008 and post-2008 - a distinction that is likely to be associated with the onset of the GFC.

While the 2001/02 forecast error is negative $\$ 76$ million, the subsequent pre-GFC forecast errors are positive. Quite clearly, Treasury was consistently underestimating company income-tax receipts. By contrast, the post-GFC forecast errors are negative. The forecast error in 2008/09 is $\$ 12.8$ billion, while the one-year revision from $2008 / 09$ to $2009 / 10$ is $\$ 25.8$ billion. That pattern of error is consistent with the notion that Treasury was surprised by the onset of the GFC but rapidly updated its estimates of revenue given the GFC had occurred.

There is, however, something unusual in the 2010/11 budget: having seen company income-tax receipts rapidly decline, the Treasury increased the forecast from $\$ 55.7$ billion in $2009 / 10$ to $\$ 66.5$ billion in $2010 / 11$, only to actually collect $\$ 56.3$ billion. It appears that company taxable income did not recover as quickly as the Treasury had expected. Similarly in 2010/11, Treasury had expected company income-tax receipts of $\$ 78$ billion in 2011/12, while the latest estimate of receipts for that year is $\$ 67.5$ billion. In other words, it appears that company income-tax receipts are taking longer to recover than Treasury expected.

The important question is whether these forecast errors are large or small. One way to evaluate the relative size of the errors is to examine their cumulative size. Prior to the GFC the cumulative underestimate of revenue is some $\$ 15.4$ billion (over seven years, an average error of $\$ 2.2$ billion per annum), while the cumulative overestimate following the GFC is $\$ 24.8$ billion (over three years, an average error of $\$ 8.3$ billion per annum). Looking at the one-year revision data, the cumulative pre-GFC changes are $\$ 25.5$ billion, while those of the post-GFC period are $\$ 18.2$ billion. These sums of money are not trivial. 
Agenda, Volume 19, Number 2, 2012

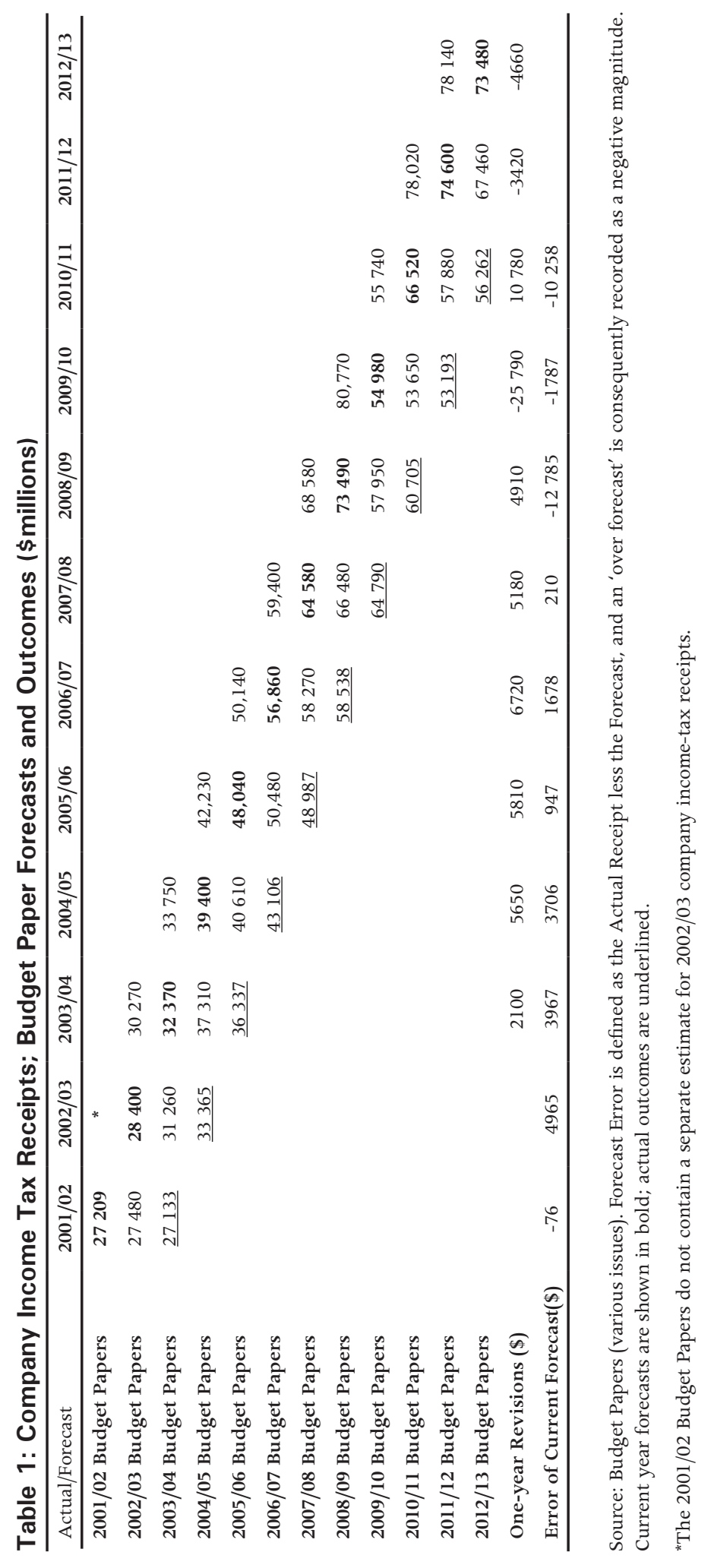




\section{Does Treasury model the company tax base?}

Since 2007 Treasury has published at least three papers measuring company tax rates across industry within Australia (Clark, Pridmore and Stoney 2007; Greagg, Parham and Stojanovski 2010; and Clark, Greagg and Leaver 2011). These papers provide an insight into Treasury's tax methodology.

Clark, Pridmore and Stoney (2007: 5) indicate that it is common practice to estimate the effective [company] tax rate by expressing company tax collections as a percentage of GOS, in large part because GOS is readily and publicly available'. Greagg, Parham and Stojanovski (2010: 95) argue that GOS is not an appropriate measure of taxable income as it excludes some sources of taxable income while also excluding some deductable company expenses. Clark, Pridmore and Stoney (2007: 11-12) discuss how GOS can be adjusted to derive a measure of 'nominal [company] profit' or 'nominal economic profit' and that measure does appear to generate an effective tax rate close to the statutory rate after 2000/01. It is this 'validation' that provides Treasury with the confidence that its adjustments to GOS provide a reasonable approximation to taxable company income.

It is very likely that Treasury does not model the company tax base but, instead, forecasts corporate GOS and then makes various ad hoc adjustments to proxy for taxable company income. It is quite clear that the Treasury's starting point, if not its end point, is a measure of GOS. To the extent that adjustments are made, it is not clear what they are or how they are undertaken, and the results of these adjustments do seem to vary from Treasury paper to Treasury paper.

Despite the limitations of GOS as a measure of taxable company income, the two variables do appear to be highly correlated with each other over long periods of time. Figure 1 shows a time series of private GOS and taxable company income, collected from the Australian Taxation Office (ATO) for the period 1989/90 to 2009/10. Unfortunately, ATO data are not (yet) available for the period after $2009 / 10$. 


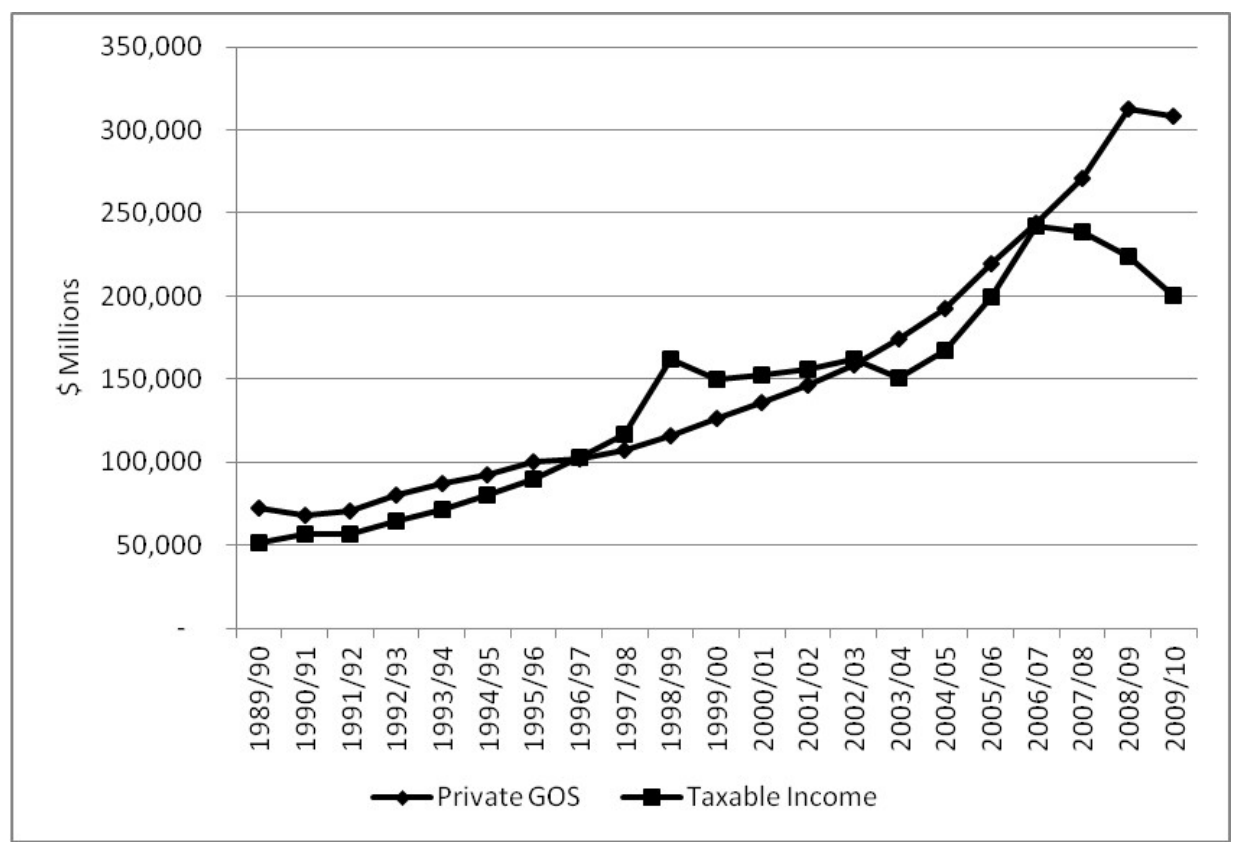

Figure 1: Private Gross Operating Surplus and Taxable Income

\section{Source: ATO Taxation Statistics and ABS 5206.0 table 7.}

There are, however, deviations between the two series. The first deviation occurs in 1998/99 and taxable income is somewhat flat until 2003/04 while GOS continues to grow. After 2003/04, company income grows faster than does GOS and it is unsurprising that Treasury consistently underestimates company income-tax receipts in that period.

It is in the post-GFC era that we observe the second and large deviation between the two series. That deviation begins in 2006/07. In the next year, the forecast error (shown in Table 1) is still positive, albeit small. By 2008/09 the two series have deviated quite substantially and the forecast error is a massive negative $\$ 12.8$ billion. It is here that the mechanism whereby Treasury translates economic forecasts into forecasts of taxable income has broken down. To be fair, it is unlikely that anybody would have realised this had happened at that time. Consistent with that view, the forecast error in 2009/10 is much smaller while the one-year revision is large.

Unfortunately, that argument does not explain the massive forecast error in 2010/11. The contrast between the forecast error and the one-year revision does suggest a change in forecast method or a political intervention to improve the reported budget figures. 


\section{Why does this matter?}

The fact that Treasury does not model the actual company tax base has important consequences. In the first instance the Treasury method can lead to significant forecast errors. In addition to undermining the budget process and making it difficult for government to pursue responsible and prudent fiscal policy, significant forecast errors also undermine Treasury's credibility. After a series of large forecast errors and subsequently unexpectedly large surpluses, John Stone (2007: 19) asked the question: 'Can it be, people are asking, that the Treasurer, knowing that even bigger forecast surpluses would produce irresistible pressure for the personal income tax rate scale reforms that he seems determined not to give us, is instructing his department to produce these latterday "rubbery figures"?'

I believe that Stone's concerns were unfounded. It is far more likely that the Treasurer intervened in the 2010/11 year to produce a 'rubbery' forecast than the scenario Stone invites us to consider.

A far greater problem revolves around policy. By forecasting growth rates and not modelling the actual tax system, Treasury does not have a good understanding of the operation of the tax system. This deficiency was well illustrated during the mining tax debate in 2010. Following the Henry Review the Rudd government had proposed a new tax on mineral rents. Part of the argument for a new tax related to the view that mining companies did not pay enough company tax.

The Henry Review first cited - and misinterpreted - a US study by Markle and Shackelford (2009) that suggested that Australian mining firms paid an effective tax rate of 17 per cent (see Mann and Coorey 2010). Treasurer Wayne Swan (2010) subsequently relied on this study to argue:

It's also the case that mining companies operating in Australia get a big discount on the company tax they pay because of very generous tax concessions they get at the expense of Australian taxpayers.

... wholly-domestic mining companies paid an effective tax rate of only 17 per cent and multinational mining companies paid an effective tax rate of only 13 per cent - both dramatically below the headline company tax rate of 30 per cent.

At the same time, the then Deputy Prime Minister, Julia Gillard, told the Nine Network that mining companies paid 17 per cent tax, 'These are the cold, hard facts - the truth' (AAP 2010). 
That both Julia Gillard and Wayne Swan did not actually understand the paper they were citing is not a reflection on them: the paper consisted of a complex econometric analysis. What is problematic is that Treasury had misinterpreted the results.

Treasury research also concludes that mining firms pay low effective tax rates (Greagg, Parham and Stojanovski 2010; and Clark, Greagg and Leaver 2011). But the results in these papers are inconsistent with ATO data showing that the mining industry paid an effective tax rate of 28.5 per cent in 2009/10. Confirmation bias led Treasury to misinterpret Markle and Shackelford (2009), and uncritically accept a result that should have been questioned. An understanding of the actual company tax base would have avoided that error. Certainly it would not have led to the Treasurer claiming that mining companies have generous tax concessions. But how else could Treasury explain its own results?

\section{Conclusion}

Treasury has made large and persistent forecast errors when forecasting company tax receipts. The approach of forecasting growth and then making ad hoc adjustments to get to a receipts forecast may well be the most effective technique Treasury can employ. The alternative would be to employ a bottomup technique that would likely be complex and expensive. There are severe limitations, however, to the Treasury methodology. Discrepancies in growth rates between GOS and taxable income will lead to massive errors - as we have seen since 2001. At least we now understand why the errors were made: it is less likely a case of political interference than of genuine error.

By forecasting aggregates and not modelling the tax base, Treasury has little understanding of the tax base itself. This reduces Treasury effectiveness in proposing policy and, more importantly, avoiding policy error.

\section{References}

AAP 2010, 'Mining companies pay only 13\% tax: Gillard', Sydney Morning Herald, 23 May 2010.

Australian Bureau of Statistics 2012, 5206.0 Australian National Accounts: National Income, Expenditure and Product. Available at: www.abs.gov.au

Australian Taxation Office 2012, Taxation Statistics 2009/10. Available at: www. ato.gov.au 
Clark, J., Greagg, P. and Leaver, A. 2011, 'Average rates of company tax across industries revisited', Economic Roundup, September: 157-67.

Clark, J., Pridmore, B. and Stoney, N. 2007, 'Trends in aggregate measures of Australia's company tax level', Economic Roundup, Winter: 1-28.

Greagg, P., Parham, D. and Stojanovski, P. 2010, 'Disparities in average rates of tax across industries', Economic Roundup, Winter: 91-103.

Mann, S. and Coorey, P. 2010, 'Researcher says $17 \%$ tax rate was "out of context"', The Age, 25 May 2010.

Markle, K. and Shackelford, D. 2009, 'Do multinationals or domestic firms face higher effective tax rates?', NBER Working Paper Series, no. 15091.

Stone, J. 2007, 'Mr Costello's repeated budget failure', National Observer 73: $13-24$.

Swan,W.2010, Treasurer'sEconomic Note, no.20(23 May 2010). Availableat: http:// treasurer.gov.au/wmsDisplayDocs.aspx?doc=economicnotes/2010/020.htm \&pageID $=012 \& \min =$ wms $\&$ Year $=2010 \&$ DocType $=4$

Uren, D. 2012, 'Rosy forecasts prompt Treasury review', The Australian, 31 May 2012.

Uren, D. and Creighton, A. 2012, 'Flawed tax figures hide budget pain as Treasury misses revenue tumble', The Australian, 18 April 2012. 